\title{
Epidemiology, virology, transmission, clinical manifestation and vaccine for hepatitis virus $B: a$ review
}

\begin{abstract}
Hepatitis B virus (HBV) is a DNA virus of the family Hepadnaviridae and the causative agent of hepatitis B infection. Hepatitis B is one of the most common infectious diseases in the world and a major health problem. The most common route of transmission is perinatal or the infection acquired during the pre-school years. The virus has caused severe endemic in parts of Africa and Asia. The prevalence of HBV varies between $2 \%$ in developed countries where the prevalence is low to about $8 \%$ in developing countries where infection is endemic with sex, age and socio-economic status as important risk factors for infection. Signs and symptoms are less common in children than adults. Anorexia, malaise, fever, muscle or joint pain, nausea, diarrhea and abdominal tenderness are early symptoms. Fullness in the right upper abdominal quadrant is also felt. During this period the urine is dark, and the feces may become pale and odiferous as there is increasing liver involvement. The paper reviews the epidemiology, virology, transmission, clinical manifestation and vaccines for hepatitis virus B.
\end{abstract}

Keywords: epidemiology, hepatitis B, transmission, vaccines, virology, virus
Volume 2 Issue 3 - 2018

\author{
Zage AU,' Ali M, ${ }^{2}$ Diso SU ${ }^{3}$ \\ 'Department of Microbiology, Kano University of Science and \\ Technology Wudil, Nigeria \\ ${ }^{2}$ Department of Biological Sciences, Federal University Gusau, \\ Nigeria \\ ${ }^{3}$ Department of Pharmaceutical Technology, School of \\ Technology, Kano State Polytechnics, Nigeria
}

\section{Correspondence: Muhammad Ali, Department of Biological} Sciences, Federal University Gusau, Nigeria, Email alinuhd4real@gmail.com

Received: September 22, 2018 | Published: November 15, 2018

\section{Introduction}

Hepatitis B virus abbreviated as HBV is classified as DNA virus belonging to the family Hepadnaviridae. It is the causative agent of Hepatitis B disease. The disease is considered as one of the most common infectious worldwide and a major health problem. According to World Health Organization, about 2 billion people worldwide are infected with Hepatitis B virus infection, and about 350 million people are chronically infected with the disease and are also at risk for HBV related liver diseases such cirrhosis and hepatocellular carcinoma. ${ }^{1}$ Hepatitis B virus infection is 50 to 100 times more infectious than HIV/AIDS and 10 times more infectious than Hepatitis $\mathrm{C}$ virus (HCV) with many carrier of the not realizing they are infected with the virus. Hepatitis B Virus is an important cause of many liver related diseases in such a way that the chronic infection of the disease cause death associated with liver failure, liver cancer and cirrhosis. ${ }^{2}$ Hepatitis B virus has caused severe endemic in most part of Africa and Asia. ${ }^{3}$ The prevalence of the disease varies between 2 in advanced countries while the prevalence is about $8 \%$ in developing countries where infection is highly endemic with age, sex and socioeconomic status as the important risk factors for the diseases. ${ }^{4}$ The predominant mode of transmission of HBV correlates with degree of its endemicity. The disease has major impact on health and economy of many countries and as well the severity of the infection is mostly variable and often unpredictable. The disease has very low infectious dose in the sense that practice like sharing of razor blade or tooth brush can transmit the infection. ${ }^{5}$

The Hepatitis B viruses are found in blood and can be transmitted sexually. This implies that the virus spread through contaminated blood or other body fluid such as vaginal secretion, saliva, sweat, semen, urine, breast and feaces. ${ }^{5}$ The transmission of the disease can occur through various sources such as using the same syringe as an infected person, from blood transfusion, from mother to child mother to child during childbirth, occupational exposure, during medical procedures and during sexual intercourse.The Hepatitis B virus shared lots of similar mode of transmission with HIV. ${ }^{6}$ Currently, there are four recognized modes of transmission (Viral Hepatitis Prevention Board, 1996) which are; from mother to child at birth (prenatal), by contact with infected person (horizontal), by sexual intercourse and through transfusion or exposure to contaminated blood or other body fluid. The Hepatitis B virus can remain viable and infectious on non-living tissues for about 7 days and as result, transmission of the disease may occur directly through the contaminated surface and other objects such as tooth brush, baby bottles, razors, eating utensil, hospitals equipments, or by contact with open skin or mucous membrane. ${ }^{7}$ The disease affects people of all age groups, but in most studies conducted recently HBV infection is predominant in young adults who acquire the infection through sexual intercourse or through use of contaminated objects. ${ }^{1}$ Most people who become infected with $\mathrm{HBV}$ can be able to get rid of the virus from their blood stream within 6 month of post infection and develop immunity. Those who have not cleared the virus after 6 month are considered to have been infected chronically. There is variability in the death risk from HBV related cancer or cirrhosis. The death risk is about $25 \%$ for persons who acquired chronic infection at childbirth while $8-10 \%$ of the general population in developing countries become more chronically infected when acquire the infection during childhood. ${ }^{2,8}$

\section{Hepatitis B infection}

Hepatitis B is considered as a serious liver disease caused by DNA virus called hepatitis virus. The disease is transmitted from one person to another via human body fluids such as saliva, blood, semen and serum. Due to the infectivity of the disease, it is seen as public health problem worldwide. The transmission method include perinatal i.e. 
through mother to baby, use of contaminated piercing objects such as razor blade, syringe and brush and through sexual intercourse. ${ }^{9}$ There are more than 2 billion people worldwide infected with $\mathrm{HBV}$ at some time or other in their life and approximately about 350 million of the infected individuals are chronically infected with the disease. ${ }^{9}$ About $25-30 \%$ of the chronically infected individual dies as the consequence of the infection. ${ }^{10}$ The infected individuals are at high risk of the disease and death from liver cirrhosis and liver cancer kill more than one million infected person per year. ${ }^{10}$

\section{Hepatitis B virus (HVB)}

The hepatitis B virus is small DNA virus with unusual features almost similar to retroviruses. ${ }^{11}$ It is prototype virus of the family Hepadnaviridae. There are several related virus similar to HBV which almost found in woodchucks, ground squirrels, tree squirrels, pecking ducks, and herons. Based on the sequence comparison of their gene, hepatitis B virus is classified into eight genotype i.e. hepatitis A to $\mathrm{H}$ and each genotype has a distinct geographic distribution. ${ }^{11}$ Three of the types of viral particle are detected in infectious serum using electron microscopy while two of the viral particles are smaller spherical structure with a diameter of about $20 \mathrm{~nm}$ and filament of variable length with a width of about $22 \mathrm{~nm} .{ }^{12}$ The filaments and spheres are composed of hepatitis B surface antigen (HBsAg) and host derived lipid without viral nucleic acid and are therefore non-infectious. ${ }^{13}$ The infectious hepatitis B virion is called Dane particle. The Dane particle has a spherical, double-shelled structure of about $42 \mathrm{~nm}$ in diameter which consists of a lipid envelope containing HBsAg that surround an inner nucleocapsid which composed of hepatitis B core antigen ( $\mathrm{HBcAg}$ ) complexes with virally encoded polymerase and the viral DNA genome. The genome of HBV is a partially double-stranded circular DNA of about 3.2 kilobase $(\mathrm{kb})$ pairs. The viral polymerase is covalently attached to the 5 end of the minus strand. ${ }^{14}$

The viral genome encodes four overlapping open reading frames (ORFs: $S, C, P$, and $X$ ). ${ }^{11,12}$ The $S$ ORF encodes the viral surface envelope proteins, the HBsAg, and can be structurally and functionally divided into thepre-S1, pre-S2, and S regions. The core or $C$ gene has the precore and core regions. Multiple in-frame translation initiation codons are a feature of the $S$ and $C$ genes, whichgive rise to related but functionally distinct proteins. The $C$ ORF encodes either the viral nucleocapsid $\mathrm{HBcAg}$ orhepatitis $\mathrm{B}$ e antigen $(\mathrm{HBeAg})$ depending on whether translation is initiated from the core or precore regions, respectively. The core protein has the intrinsic property to self-assemble into a capsid-like structure and contains a highly basic cluster of amino acids at its $\mathrm{C}$ logic function of $\mathrm{HBxAg}$ in the viral life-cycle remain largely unknown. However, it is well established that HBxAg is necessary for productive HBV infection in vivo and may contribute to the oncogenic potential of $\mathrm{HBV}{ }^{15}$ The precore ORF, codes for a signal peptide that directs the translation product to the endoplasmic reticulum where the protein is further processed to form the secreted $\mathrm{HBeAg}$. The function of $\mathrm{HBeAg}$ remains largely undefined, although it has been implicated as an immune tolerogen, whose function is to promote persistent infection. ${ }^{16}$ The polymerase (pol) is a large protein (about 800 amino acids) encoded by the $P$ ORF and is functionally divided into three domains: the terminal protein domain, which is involved in encapsidation and initiation of minus-strand synthesis; the reverse transcriptase (RT) domain, which catalyzes genome synthesis; and the ribonuclease $\mathrm{H}$ domain, which degrade spregenomic RNA and facilitates replication. ${ }^{17}$ The HBV $X$ ORF encodes a $16.5-\mathrm{kd}$ protein $(\mathrm{HBxAg})$ with multiple functions, including signal transduction, transcriptional activation, DNA repair, and inhibition of protein degradation. ${ }^{17-20}$ The mechanism of this activity and the biologic function of HBxAg in the viral life-cycle remain largely unknown. However, it is well established that $\mathrm{HBxAg}$ is necessary for productive $\mathrm{HBV}$ infection in vivo and may contribute to the oncogenic potential of $\mathrm{HBV} .^{19,20}$

Other functionally important elements found in the HBV genome include two direct repeats i.e. DR1 and DR2 in the 5 end of the plus strand, which are required for strand specific DNA synthesis during viral replication. ${ }^{21}$ There are two enhancer elements in the virus designated as En1 and En2 which confer liver specific expression of viral gene products. ${ }^{22}$ A glucocorticoid-responsive element (GRE) sequence within $\mathrm{S}$ domain, ${ }^{23}$ A polydenylation signal within the core gene, and a post-transcriptional regulatory element overlapping En1 and part of HBxAg OFR have also been described. ${ }^{24}$ The initial phase of hepatitis B virus involves the attachment of mature virions to the membranes of the host cell and likely involving he pre-S domain of the surface protein Figure $1 .^{25}$

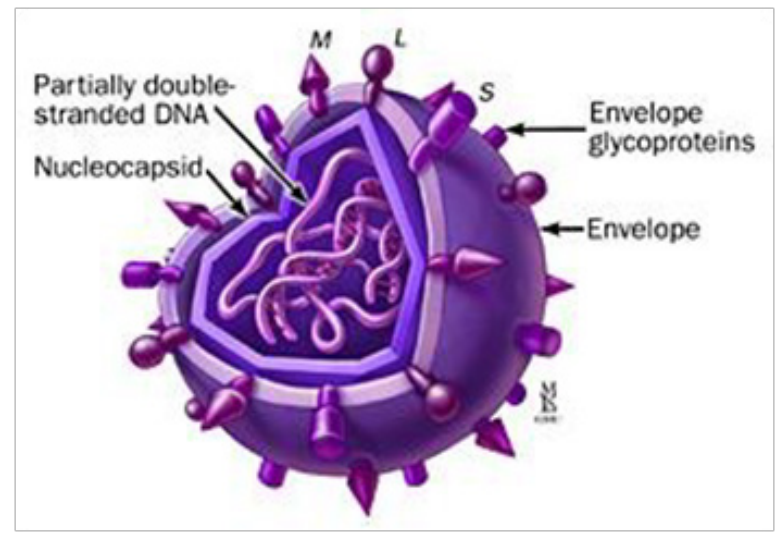

Figure I Hepatitis B virion.

\section{Epidemiology of hepatitis $B$ virus}

Hepatitis B infection is considered as a disease of significant health importance as there are more than 2 billion infected persons worldwide. ${ }^{9}$ The disease accounted for about $40 \%$ of all hepatitis cases in the united State. ${ }^{26}$ According to Centre for Diseases Control and Prevention (CDC), the risk factors associated with Hepatitis B cases in the United State include 36\% spread by heterosexual activity, 13\% by intravenous drug use or injections, $11 \%$ by homosexual activity, $3 \%$ by domestic contact with contaminated objects and $2 \%$ through health care employment while $33 \%$ by unknown causes. ${ }^{27}$ However, there is variation in the actual percentage of each group in different publications, but this percentage shows general trend of the infection. The commonly accepted high risk group worldwide include; children born to hepatitis B positive mother, homosexual men, health care workers, intravenous drug users, hemodialysis patients, household contact, institutionalized populations, sexual partners of infected person, recipients of certain plasma derived products and population living in area where the disease is endemic. In the United State alone, about $89 \%$ of the HBV cases occur in peopled aged between 15 to 44 years old ${ }^{28}$ however, vertical transmission is very common. ${ }^{26}$ In addition to that, the hepatitis B virus is important to health care workers and it accounts for the death of about 300 health workers annually. ${ }^{26}$ The horizontal transmission of the infection is through 
blood and blood products such as serum and plasma. The danger of HBV infection acquired through blood transfusion dropped drastically to about $0.002 \%$ due to thorough serological screening procedure ${ }^{28}$ and also due the reduction of using blood from paid donors. ${ }^{29}$ Hepatitis $\mathrm{B}$ infection can also be acquired through casual contact of an infected fluid through trivial and break in the skin. ${ }^{29}$ On the other hand, the danger of hepatitis B through contaminated needle stick and exposure of health care workers was found to account for about $6-24 \%$ of the cases. According to Larssen and Larsen, ${ }^{26}$ the minimum infective dose of infected sera is $1 \times 10^{-6} \mathrm{ml}$ and according to them, the infectious levels of the virus are also found in feces, urine, saliva, serum, semen and vaginal secretion (Figure 2).

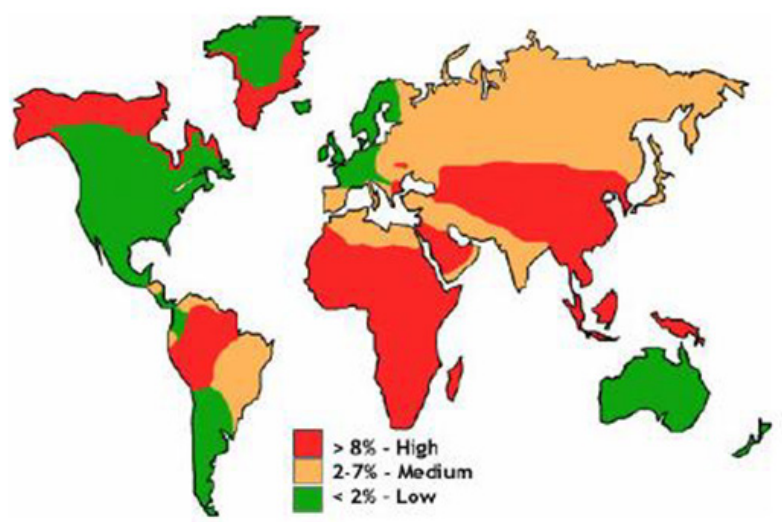

Figure 2 Geographical distribution of hepatitis B infection.

\section{Person at risk}

I. Children born to hepatitis B positive mother

II. Sexual partner to infected person

III. Person with more than one sexual partners

IV. Person infected with sexually transmitted diseases (STDs)

V. Homosexual men

VI. Person using injection drugs

VII. Domestic contact of infected person

VIII. Health care and public safety personnel exposed to blood

IX. Hemodialysis patients

X. Residents and staff of facilities for developmentally disabled persons.

XI. Travelers to the region of high or intermediate rate of hepatitis B infection. ${ }^{30}$

\section{Transmission route of hepatitis $B$ virus}

The transmission route for hepatitis B infection is by contact with infected blood, semen and other fluid primarily through;

i. Children born to hepatitis B positive mother Sexual intercourse with hepatitis B positive person Sharing of contaminated objects such as syringes, needle, razor blade or injection drug equipments Needle sticks or other sharp objects such as razor blade. ${ }^{30}$

\section{Transmission of hepatitis B virus}

Hepatitis B virus predominantly spread by percutaneous or mucosal exposure to infected blood and other body fluids such as saliva, vaginal, menstrual and seminal fluids which have all been implicated as vehicles of human transmission. ${ }^{31}$ Hepatitis B may be transmitted sexually especially in unvaccinated person who have sex with men and heterosexual person with more than one sex partner or by contact with sex worker. HVB infection among adults leads to chronic hepatitis in less than $5 \%$ of the cases. ${ }^{31}$ Transmission of the virus may also result from accidental inoculation of small amount of blood or fluid during surgical, medical or dental procedures or from sharp and piercing objects such as razor blade, needle or similar objects contaminated with infected blood or fluid which transmit the virus through the following practices; tattooing, intravenous and percutaneous drug abuse, use of inadequately sterilized syringes and needles, body piercing and acupuncture..$^{31}$

\section{Perinatal transmission of HBV}

In many part of the world, perinatal transmission is the major route of HBV transmission, and an important factor considered in maintaining the reservoir of the infection in some part of the world particularly China and South East Asia. In the absence of protective treatment of the infection, a large population of viraemic mothers especially those that are positive for $\mathrm{HBeAg}$, transmit the infection to their infants during or shortly after birth. ${ }^{32}$ There is increase in the rate of perinatal infection if the mother has acute hepatitis $\mathrm{B}$ infection during second or third trimester of pregnancy or within two month of delivery. However, HBV can the fetus in the uterus and this appears to be rare and is generally associated with placental tears and ante-partum haemorrhage. The risk of developing chronic infection is about $90 \%$ following perinatal infection up to duration of 6 months but decreases to about $20-60 \%$ between ages of 6 months to 5 years. ${ }^{32,33}$

\section{Horizontal transmission of HBV}

Horizontal transmission of HBV include transmission through household, intra-familial especially child-to-child. About $50 \%$ of the infection in children cannot be accounted for by mother to infant transmission and in many endemic region, prior to the introduction of neonatal vaccination, the prevalence peaked among children aged between 7 to 14 years. ${ }^{34}$

\section{Symptoms and sign of hepatitis B infection}

After exposure to hepatitis B virus, the incubation period before the exposure of the symptoms ranges between 60 to 180 days. ${ }^{26}$ The infection to disease ratio for the infection is thought to be $6: 1$ or $7: 1$ and as result, many infected individuals show clinical symptoms only. ${ }^{35}$ The early symptoms for hepatitis B infection include malaise, fever, nausea, anorexia, and abdominal tenderness. Fullness in the right upper abdominal quadrant is also felt. ${ }^{35}$ Hepatomegaly occurs in almost $70 \%$ of the patients concurrent with jaundice and hepatosplenomegaly also occur in most infected children. ${ }^{36}$ Frequently, the patient feels better for 24 to 48 hours and then jaundice develops. Due to the liver involvement during this period, the urine become dark and the feces may become pale and odiferous. Full recovery may take 4 to 6 weeks with malaise lasting longer in many cases. These symptoms are almost similar to those seen with hepatitis A infection but more severe with 
hepatitis $\mathrm{B}$ and in addition, pathology due immune complex formation occurs. These immune complexes in hepatitis B can deposit thereby, causing transient polyarthralgials and serum sickness like rashes in most patients. ${ }^{37}$ Hepatitis B infection can be manifested in three ways namely; acute, fulminant and chronic infections. In acute infection, infected individual can recover fully and consists most of the cases. The lesion observe in the liver during acute hepatitis include mild necrosis of liver parenchymal cells, lymphoidal cell infiltration and proliferation of liver macrophage called Kupffer cells. ${ }^{35}$

Fulminant infections cause cerebral function change, massive liver necrosis, hepatic failure and death in some cases. These symptoms are rare and occurring in less than $1 \%$ of the cases. ${ }^{35,36}$ In individuals with these symptoms, the disease onset is always sudden and may result in sudden collapse due to fatigue. Other symptoms in fulminant infection include; hepatomegaly and rapid onset of jaundice. ${ }^{36} \mathrm{Chronic}$ infection is defined as the presence of HBsAg in the serum of the patient for period of 6 months or longer after preliminary laboratory finding. It occurs in about $5-10 \%$ of hepatitis B cases and are typically connected to development of hepato cellular carcinoma and liver cirrhosis. ${ }^{26}$ Immuno-compromised patients, infants and children of less than 6 years show greatest of developing chronic hepatitis B infection. ${ }^{38}$ In chronic hepatitis B infection, the virus is not cleared due to the absence of development of sufficient protective immune response. The liver pathology may increase and as well the increase in liver necrosis, fibrosis and collapse of reticular frame work may occur. ${ }^{35}$

Hepatocytesmay may appear abnormal due to cytoplasmic HBsAg, andare called ground glass hepatocytes. This syndrome is called Postnecrotic liver necrosis. ${ }^{35}$ Small percentage of patients with chronic hepatitis may become HBsAG negative and this is thought to be a cure from chronic infection. The chronic Hepatitis B infection is strongly linked to development of hepato-cellular carcinoma. ${ }^{39}$ The oncogenes are not known to be present in Hepatitis B virus. The association of hepato-cellular carcinoma and Hepatitis B infection may be direct in which liver necrosis is followed by intense proliferations of hepatocytes during regeneration and this accelerated proliferation may be related to abnormal cell development. ${ }^{35}$ Hepato-cellular carcinoma is the leading cause of death in an area where hepatitis b is endemic. ${ }^{40}$ The infected people via maternal to neonatal transmission show high risk of hepato-cellular carcinoma. ${ }^{40}$

\section{Hepatitis $B$ vaccines}

Hepatitis B vaccine is about $80-100 \%$ effective in managing hepatitis infection or clinical hepatitis in those who a complete dose of. ${ }^{41}$ The two major types of hepatitis B vaccine available are;

\section{i. Plasma derived vaccine, and \\ ii. Recombinant vaccine.}

These two vaccines show no differences in terms of reactogenicity, duration or efficacy of protection, however, their thermo-stability is very similar. Both the vaccines type tolerate temperature of up to $45^{\circ}$ $\mathrm{C}$ for a period of one week and up to $37^{\circ}$ for one month duration with without changing rectogenicity or immunogenicity. ${ }^{41}$ The plasmaderived vaccines are prepared from purified HBsAg obtained from the blood plasma of infected person with chronic HBV infection. The vaccines have been commercially available worldwide since 1982. Due to extensive purification of the vaccine, potential residual infectious particles are eliminated by a number of inactivation steps. Aluminium hydroxide or Aluminium phosphate is added to the vaccine as adjuvant and for multi dose vials; thiomersal is also used as preservatives. ${ }^{42}$

On the other hand, the recombinant hepatitis $\mathrm{B}$ vaccine uses HBsAg synthesized in mammalian cells or yeast into which the HBsAg gene has been inserted by plasmids. The transformed cells are grown in large vessels, and the expressed HBsAg self-assembles into immunogenic, spherical particles that expose the immunogenic $a$ antigens. ${ }^{41,43}$ The recombinant particles are different from the natural ones only in the glycosylation of HBsAg. Following thorough purification from host cell components, alum is added. Due to the differences in the manufacturing process of the vaccine, the quantity of HBsAg protein per dose of vaccine that will induce a protective immune response differs among the various vaccine products. ${ }^{41}$ As result of this, there is no international standard for vaccine potency

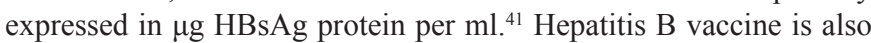
available as monovalent formulations or in fixed combination with other vaccine, including DTwP, DTaP and IPV. When immunizing hepatitis B virus at birth, only monovalent hepatitis B vaccine should be used; other antigens found in combination vaccines are presently not approved for use at birth. ${ }^{44}$

\section{Conclusion}

Hepatitis B virus abbreviated as HBV is classified as DNA virus belonging to the family Hepadnaviridae. It is the causative agent of Hepatitis B disease. The disease is considered as one of the most common infectious worldwide and a major health problem. According to World Health Organization, about 2 billion people worldwide are infected with Hepatitis B virus infection, and about 350 million people are chronically infected with the disease and are also at risk for HBV related liver diseases such cirrhosis and hepatocellular carcinoma. The unique features of its replication cycle confer a distinct ability of the virus to persist in infected cells. Virological and serological assay have been developed for various type of HBV associated diseases and also for the treatment of hepatitis B infection. $\mathrm{HBV}$ infection leads to a wide spectrum of liver disease ranging from acute to chronic hepatitis, cirrhosis and hepato-cellular carcinoma. Acute hepatitis B infection can be symptomatic acute hepatitis. Most adults infected with the virus recover, but about 5 to $10 \%$ are unable to clear the virus and hence become chronically. Most of the chronically infected persons present mild liver diseases with little or long term morbidity or mortality. Other individual with chronic hepatitis B infection develop active diseases which can progress to cirrhosis and liver cancer. These patients require careful monitoring and warrant therapeutic intervention. Extra-hepatic manifestations of the diseases are very rare but can be difficult to diagnose and manage.

\section{Acknowledgements}

None.

\section{Conflict of interest}

The authors declare that there is no conflict of interest.

\section{References}

1. Shepard CW, Simard EP, Finelli L, et al. Hepatitis B virus infection: Epidemiology and Vaccination. Epidemiol Rev. 2006;28:112-25. 
2. Weinbaum CM, William I, Mast EE, et al. Recommendations for identification and public health management of persons with chronic hepatitis B virus Infection. Morbidity and Mortality Weekly Report. 2008;57:1-20.

3. DrosteinC, Nippraschk T, Maregold C, et al. Prevalence of hepatitis B virus DNA in anti-HBV-Positive/HBS Ag negative sera correlates with HCY but not HIV Serostatus. J ClinVirol. 2004;29:59-68.

4. Adoga MP, Gyar SD, Pechulano S, et al. Hepatitis B virus infection in apparently healthy urban Nigerians: data from prevaccination tests. $J$ Infect in Dev Ctries. 2010;4(6):397-400.

5. Odusanya OO, Alufohai FE, Maurice FP, et al. Prevalence of hepatitis B surface antigen in vaccinated children and controls in rural Nigeria. Intl J Infect Dis. 2005;9(3):139-143.

6. Chang M. Hepatitis B Virus infection. Seminars in Fetal and Neonatal Medicine. 2007;12(3):160-167.

7. Willey JM, Sherwood LM, Woolverton CJ. The History and scope of Microbiology: I ntroduction of Microbiology. In: Willey JM, et al, Editors. Prescott's Microbiology. New York: The McGraw Hill Companies. International Edition. 2011;1-21.

8. World Health Organization. Hepatitis B Fact sheet No. 204. 2009.

9. Kane M. Global programme for control of hepatitis Binfection. Vaccine. 1995;13(Supp1):S47-S49.

10. World Health Organisation. Hepatitis B. Fact sheet WHO/204. World Health Organisation. Geneva. 2000.

11. Howley PM, Griffin DE, Martin MA, et al. Fields Virology. Philadelphia, PA: Lippincott-Raven Publishers. 2001.

12. Hollinger FB, Liang TJ. Hepatitis B virus. In: Knipe DM, et al, Editors. Fields Virology. Philadelphia. PA: Lippincott-Raven Publishers. 2001;2971-3036.

13. Gavilanes F, Gonzales-Ros A, Peterson D. Structure of hepatitis B surfaceantigen: characterization of the lipid components and their associationwith the viral proteins. J Biol Chem. 1982;257:7770-7777.

14. Gerlich W, Robinson WS. Hepatitis B virus contains protein attached tothe 5_ end of its complete strand. 1980.

15. Hatton T, Zhou S, Standring DN. RNA- and DNA-binding activities inhepatitis B virus capsid protein: a model for their roles in viral replication. J Virol. 1992;66:5232-5241.

16. Milich D, Liang TJ. Exploring the biological basis of hepatitis B e antigen in hepatitis B virus infection. Hepatology. 2003;38:1075-1086.

17. Zhang Z, Torii N, Hu Z, et al. X-deficient woodchuck hepatitisvirus mutants behave like attenuated viruses and induce protectiveimmunity in vivo. J Clin Invest. 2001;108:1523-1531.

18. Cross JC, Wen P, Rutter W. Transactivation by hepatitis B virus X proteinis promiscuous and dependent on mitogen-activated cellular serine/ threoninekinases. Proc Natl AcadSci USA. 1993;90(17):8078-8082.

19. $\mathrm{Hu} \mathrm{Z}$, Zhang Z, Kim JW, et al. Altered proteolysis andglobal gene expression in hepatitis $\mathrm{B}$ virus $\mathrm{X}$ transgenic mouse liver. $J$ Virol. 2006;80:1405-1413.

20. Bouchard MJ, Schneider RJ. The enigmatic X gene of hepatitis B virus. $J$ Viro. 204;78:12725-12734.

21. Seeger C, Ganem D, Varmus HE. Genetic and biochemical evidence for the hepatitis B virus replication strategy. Science. 1986;232:477-485.

22. Yee J. A liver-specific enhancer in the core promoter region of humanhepatitis B virus. Science. 1989;246(4930):658-670.
23. Tur-Kaspa R, Burk R, Shaul Y, Shafritz D. Hepatitis B virus DNA containsa glucocortcoid response element. Proc Natl Acad Sci USA. 1986;83(6):1627-1631

24. Huang J, Liang TJ. A novel hepatitis B virus (HBV) genetic element withRev response element-like properties that is essential for expression of HBVgene products. Mol Cell Biol. 1993;13:7476-7486.

25. Klingmuller $U$, Schaller $H$. Hepadnavirus infection requires interactionbetween the viral pre-S domain and a specific hepatocellular receptor. J Virol. 1993;67:7414-7422.

26. Larssen JT, Larsen HS. Viral Hepatitis: an overview. Focus. 1995;8(3):169-173.

27. Duma R. Establishing a national universsal vaccinationprogramme. Vaccine. 1995;13(Supp1):58-60.

28. Abbott Park IL. Abbott Laboratories. 1994. 97-9375/R2-20-Jan1994.

29. Turgeon ML. Immunology \& Serology in Laboratory Medicine. Chapter 20 St. Louis: Mosby-YearBook. 1996;253-273.

30. Centre for Disease Control (CDC). Hepatitis B virus. ABC for hepatitis United State Deaptment of health and human services, Centre for Disease Control and prevention. 2016.

31. Mast EE, Alter MJ, Margolis HS. Strategies to prevent and contro hepatitis $\mathrm{B}$ and $\mathrm{C}$ virus infections: a global perspective. Vaccine. 1996;17(13-14):1730-3.

32. Beasley RP, Hwang LY, Lee GC, et al. Prevention of perinatally transmitted hepatitis B virus infections with hepatitis B immune globulin and hepatitis B vaccine. Lancet. 198312(8359):1099-102.

33. McMahon BJ, Alward WL, Hall DB, et al. Acute hepatitis B virus infection: relation of age to the clinical expression of disease and subsequent development of the carrier state. J Infect Dis. 1985;151(4):599-603.

34. Szmuness W. Recent advances in the study of the epidemiology of hepatitis B. Am J Pathol. 1975;81(3):629-50.

35. Drew LW. Hepatitis Viruses. In: Ryan K, Sherris J, Editors. Sherris Medical Microbiology: anintroduction to infectious diseases. E Norwalk, CT: Appleton \& Lange. 1994;491-501.

36. Berlin BS. Viral Hepatitis In: The Biologic and ClinicalBasis of Infectious Diseases. Philadelphia, Pa.W.B. Saunders. 1975;514-527.

37. Fenner F., White D. Medical Virology. New York: Academic Press. 1976;426-452.

38. Hyams KC. Risks of chronicity following acute hepatitisB virus infection: A review. Clinical Infectious Diseases. 1995;20:992-1000.

39. Cross TJ, Rizzi P, Horner M, et al. The increasing prevalence of hepatitis delta virus (HDV) infection in South London. J Med Virol. 2008;80(2):277-82.

40. Fenner F, White D. Medical Virology. New York: Academic Press. $1976 ; 426-452$.

41. WHO. Global Hepatitis Report. WHO. 2017;1-83.

42. Bruce MG. Antibody levels and protection after hepatitis B vaccine: results of a $30-$ year follow-up study and response to a booster dose. $J$ Infect Dis. 2016;214(1):16-22.

43. Lin AW-c. Long-term protection of neonatal hepatitis B vaccination in a 30-year cohort in Hong Kong. J Hepatol. 2013;59(6):1360-1364.

44. Poorolajal J. Long-term protection provided by hepatitis B vaccine and need for booster dose: a meta-analysis. Vaccine. 2010;8:28(3):623-31. 